\title{
Condicionantes relacionados ao uso crônico de clonazepam no Brasil: uma história de vida
}

\author{
Conditioning factors related to the chronic use of clonazepam in \\ Brazil: a life history
}

\author{
Zacarias AntonioMangini $\mathrm{Jr}^{1}$ \\ Sandra Noemi Cucurullo Caponi ${ }^{2}$
}

\begin{abstract}
Resumo
O consumo de psicotrópicos, da categoria dos benzodiazepínicos, vem alcançando proporções elevadas nos últimos anos. Dentre esses medicamentos, o fármaco clonazepam recebe destaque, ao figurar em relatórios de Organismos Internacionais como uma das substâncias mais consumidas no mundo. Em geral, os pacientes que fazem uso crônico dos benzodiazepínicos são do sexo feminino, têm idade igual ou superior a quarenta anos e utilizam o medicamento por mais de dois anos. Considerando que esses pacientes apresentam histórias de vida relacionadas a contextos sociais adversos, procurou-se analisar a interferência desses contextos na elevação do consumo de benzodiazepínicos, fenômeno que ocorre no Brasil. Para a realização dessa pesquisa, optou-se por um estudo de caso, como delineamento da modalidade de produção de conhecimento. Este estudo apresenta um caráter qualitativo, com objetivos exploratórios e descritivos, e utiliza para coleta de dados a entrevista não-estruturada, mais especificamente a técnica de pesquisa conhecida como história de vida.
\end{abstract}

Palavras-chave: Clonazepam. Contextos sociais. História de vida.

\begin{abstract}
The consumption of psychotropic drugs in the benzodiazepine category has attained high proportions in recent years. Among these medications, clonazepam stands out in reports of international agencies as one of the world's most highly consumed substances of this kind. Most patients who make chronic use of benzodiazepines are female, 40 or older, and they have used the medication for more than two years. Considering that these patients have histories related to adverse social contexts, this study analyzes the interference of these contexts in the high consumption of benzodiazepines, a phenomenon that occurs in Brazil. A case study was conducted by a qualitative nature with exploratory and descriptive purposes. Non-structured interviews were used for data collection, specifically the technique known as life history.
\end{abstract}

Keywords: Clonazepam. Social contexts. Life history.

\footnotetext{
${ }^{1}$ Universidade Federal de Santa Catarina (UFSC). Farmacêutico Bioquímico, Especialista em Saúde da Família, Mestrando em Saúde Coletiva. E-mail: manginifarma@hotmail.com.

${ }_{2}$ Universidade Federal de Santa Catarina (UFSC). Professora doutora do Departamento de Sociologia e Ciências Políticas da UFSC. E-mail: sadracaponi@gmail.com.
}

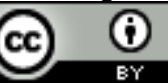

Esta obra foi licenciada com uma Licença Creative Commons - Atribuição 3.0 Não Adaptada. 


\section{Introdução}

O consumo de psicotrópicos vem alcançando proporções elevadas nos últimos anos. Dentre esses medicamentos, o fármaco clonazepam (pertencente ao grupo dos benzodiazepínicos) recebe destaque, ao figurar em relatórios de Organismos Internacionais como uma das substâncias mais consumidas no mundo. O Conselho Internacional de Controle de Narcóticos (INCB), em seu relatório publicado no ano de 2009, apresenta indícios de um abuso sistemático de preparações farmacêuticas contendo clonazepam, e aponta também a ocorrência do tráfico e do abuso da prescrição desse medicamento em muitos países. No Brasil, os dados relativos à comercialização do clonazepam apontam para um consumo superior a doze milhões de unidades desse medicamento, entre os anos de 2008 e 2009 (BRASIL, A., 2011).

A utilização dos benzodiazepínicos (BZD), por um período de tempo que ultrapasse os seis meses de tratamento preconizados na literatura, poderá levar os pacientes a quadros clínicos de dependência química, física ou psicológica. Essa dependência relacionada ao uso de BZD tende a acarretar prejuízos à saúde do paciente, no seu convívio social e na qualidade de vida do mesmo. Sendo assim, o processo de retirada dos BZD necessita ser lento e gradual, pois os efeitos colaterais severos ocorrem com frequência, decorrentes da abstinência e do chamado "efeito rebote". 3 Apesar desses medicamentos constaremna literatura como um dos mais seguros (RANG,2007), eles escondem graves problemas no seu manejo, pois as dificuldades inerentes a um quadro de dependência não prevalecem sobre os benefícios e, muitas vezes, passam despercebidas, devido à complexidade das situações envolvidas no tratamento dos pacientes.

Acompanhando a tendência do elevado consumo de BZD, verifica-se que esses medicamentos também estão entre aqueles mais prescritos por médicos que não atuam no campo da psiquiatria, além das prescrições realizadas pelos próprios psiquiatras. Esse fato coloca sob suspeita a realização dos diagnósticos mentais e a

\footnotetext{
${ }^{3}$ Efeito rebote: está relacionado ao retorno dos sintomas controlados pelo medicamento, porém, de forma muito mais intensa do que no início do tratamento, decorrente da parade, abrupta ou não, do uso de um determinado medicamento como, por exemplo, os benzodiazepínicos.
} 
prescrição dos BZD como opção de escolha para o tratamento desses transtornos, ${ }^{4}$ seja pelos médicos seja pelos pacientes. Tendo em vista esse panorama, faz-se necessário problematizar a ocorrência de um excesso na prescrição dos BZD, bem como do uso inadequado desses medicamentos por parte dos pacientes, o que poderia propiciar um ambiente favorável ao elevado consumo desses medicamentos.

Na ligação entre a prescrição excessiva e a inobservância às normas sobre o uso racional de medicamentos (BRASIL, M.,2001), há possibilidade de serem encontrados contextos sociais que não estariam sendo levados em conta pelos médicos no momento de decidir pela prescrição dos BZD. Com essa terapêutica, o médico busca atender às demandas sociais atuais, que consistem em não tolerar qualquer tipo de sofrimento por parte dos pacientes, lançando mão do uso de medicamentos, como os BZD, que contribuem para mascarar a provável ou possível raiz de seus problemas (ANGELL, 2007; CAPONI, 2012; RANG, 2007).

Em vista dessas lacunas, durante a realização deste estudo, buscou-se o entendimento das condicionantes relacionadas ao uso crônico e elevado dos BZD, por meio de uma visão que possibilitasse ao paciente apresentar o seu percurso em busca de tratamento, desde as primeiras queixas, passando pelo atendimento médico e chegando ao seu atual cotidiano da utilização do medicamento. Na ocasião deste estudo, também se optou pela história de vida como técnica de coleta de dados, uma vez que, por meiodessa técnica, o informante passa a contar a história de sua vida, suas experiências e expectativas, na construção diária de seu ambiente social.

Com base nessa perspectiva, parte-se do pressuposto de que é possível visualizar, pela ótica do paciente, a existência de condicionantes no uso crônico de BZD, além de verificar a relação destes com o elevado consumo de BZD.

\footnotetext{
${ }^{4}$ As orientações de uso mais comuns dizem respeito ao tratamento de transtornos da ansiedade (TA), transtorno do pânico (TP), fobia social (FS) e transtorno do humor (MENDONÇA; CARVALHO, 2005).
} 


\section{Objetivos e métodos}

Torna-se cada vez mais urgente questionar a vinculação dos contextos sociais, nos quais aparece o fenômeno cada vez mais generalizado de medicalização, com ossofrimentos decorrentes de conflitos ou de problemas sociais. Assim sendo, este estudo propõe o seguinte objetivo geral: analisar a interferência de contextos sociais adversos na elevação do consumo de benzodiazepínicos no Brasil.

Para atingir esse objetivo será preciso considerar cinco objetivos específicos que apontamos a seguir: 1) identificar junto ao paciente de que forma ocorreu o primeiro contato com o medicamento clonazepam; 2) apreender, pela perspectiva do paciente, as questões desencadeantes da "doença", sujeitas ao tratamento medicamentoso; 3) verificar, pela ótica do paciente, a relevância das causas sociais no diagnóstico e na escolha do tratamento; 4) compreender de que maneira o tratamento com benzodiazepínico resultou em melhora ou solução das questões desencadeantes apontadas pelo paciente; e 5) relacionar as percepções da história de vida do paciente sobre o uso do medicamento, com estudos sobre o tema.

Atingir esses objetivos exige um olhar atento para a história de vida de pacientes diagnosticados com transtorno de ansiedade, que consomem, há tempo, benzodiazepínicos. Por esse motivo, optou-se por realizar um estudo de caso, modalidade de produção de conhecimento que tem como característica a flexibilidade, sem deixar em segundo plano o rigor necessário à pesquisa científica. Segundo Yin (2001), "um estudo de caso é uma investigação empírica que investiga um fenômeno contemporâneo dentro de seu contexto, especialmente quando os limites entre o fenômeno e o contexto não estão claramente definidos". Nesse sentido, possibilita estudar em profundidade o grupo, organização ou fenômeno, levando em consideração suas múltiplas dimensões. Além disso, por se referir a um número menor de objetos, em nosso caso, um indivíduo, possibilita maior profundidade na obtenção de dados.

A técnica de coleta de dados utilizada é conhecida por história de vida, ou seja, é o relato de um narrador sobre a sua existência através do tempo, buscando reconstruir os fatos vivenciados e transmitir sua experiência adquirida. Esse tipo de técnica tem como características a informalidade, a profundidade das informações,e, 
principalmente, o foco na vida do entrevistado. A história de vida se coloca, dentre as técnicas de coleta de dados, como a que permite observar os aspectos do ponto de encontro entre o individual e o social, possibilitando conhecer a cultura na intersecção das relações, entre o que é interior e exterior para o indivíduo. Dessa forma, possibilita a apreensão do processo de mudança, tornando compreensível a dinâmica dos processos sociais (GIL, 2009).

A coleta de dados foi realizada a partir de uma unidade de farmácia de dispensação do Serviço Social da Indústria de Santa Catarina (SESI - SC). Foram estabelecidos como critérios para a seleção do informante: aquele que fizesse a aquisição do clonazepam na farmácia do SESI-SC, preferencialmente do sexo feminino, situado em uma faixa etária igual ou superior a quarenta anos e, necessariamente, em tratamento por um período superior de dois anos, considerando a possibilidade de cronificação do uso do medicamento. Os demais critérios refletem o perfil do paciente crônico, encontrado com maior frequência nos estudos visitados. ${ }^{5}$ A escolha do local se deve à vinculação do pesquisador a essa empresa, tornando possível o convite e a interação com o paciente.

A análise está ancorada no estudo de caso único, possibilitando a generalização analítica das informações obtidas por meio da história de vida do paciente. Na visão de Becker (1993), estudos individuais podem ser entendidos como peças de um mosaico, dentro do qual cada pedaço adicionado ao quadro contribuirá para a nossa compreensão do fenômeno, em sua totalidade.

O uso da técnica de história de vida possibilita ao pesquisador atravessar fronteiras na direção de terrenos tangenciados pelos relatos, levantando pressupostos em direção à verdade, mesmo que, grosso modo, fornecendo uma visão subjetiva do processo estudado. A riqueza de detalhes proporcionados por essa abordagem se mostra importante na ampliação das possibilidades, diante da estagnação e saturação das pesquisas sobre o tema em ascensão, apesar dos retornos reduzidos, no sentido de melhora do entendimento do fenômeno (BECKER, 1993).

Dessa forma, ao privilegiar intencionalmente a história de vida como estratégia da coleta de dados, buscam-se elementos para a compreensão da

\footnotetext{
5 São exemplos desses estudos: ALVARENGA, (2008), CARLINI (2006), FIRMINO (2012), MENDONÇA; CARVALHO (2005), ORLANDI, NOTO (2005) e NOTO (2002).
} 
realidade, por seconsiderar o imbricamento de fenômenos contextuais relacionados ao evento em questão (YIN, 2001).

A entrevista foi realizada com a apresentação prévia, ao sujeito da pesquisa, do Termo de Consentimento Livre e Esclarecido, visando o esclarecimento dos alcances e limites da pesquisa, bem como a preservação do sigilo. Os preceitos da bioética, representados pela autonomia, não maleficência, beneficência e justiça devem ser respeitados, a fim de preservar a entrevistada. No término do estudo, a entrevistada receberá cópia do trabalho, como contrapartida das informações prestadas. Ao final, serão estabelecidas articulações entre os dados e os referenciais bibliográficos da pesquisa, de modo a responder às questões do estudo, levantar hipóteses e interpretar os dados conclusivamente (GIL, 2009).

O material utilizado na elaboração do presente artigo foi elaborado no âmbito de uma pesquisa mais ampla, intitulada "O uso e a prescrição do rivotrilß (clonazepam) na rede básica de saúde do município de São José Titilo", aprovada pelo Comitê de Ética em Pesquisa com Seres Humanos (CEPSH) da Pró-reitoria de Pesquisa e Extensão da Universidade Federal de Santa Catarina, Processo: 716, F.R: 330666.

\section{Resultados e discussão}

A entrevista foi realizada no local de trabalho da entrevistada, após três adiamentos, quando foi possível agendar uma data para sua realização. Os adiamentos ocorreram em virtude do acúmulo de trabalho da entrevistada, ocasionado por um período de internação de aproximadamente três meses relacionado a uma crise de um quadro depressivo. Os dados foram gravados em mídia digital e posteriormente transcritos, procurando-se manter a maior fidedignidade entre o relato e a transcrição.

A história de vida da entrevistada se enquadra em um tipo de relato que poderia ser denominado como exemplar, devido à possibilidade de se fazer uma generalização do seu cotidiano com aquilo que pode vir a ser o cotidiano de milhões de pessoas que fazem uso de benzodiazepínicos no Brasil.

Sendo assim, atualmente, a entrevistada está com quarenta e um anos, é separada de seu cônjuge, não legalmente, e mora com seus dois filhos. Trabalha em 
uma universidade da região da grande Florianópolis, em Santa Catarina. Ocupa um posto no setor de ensino a distância e, para estar nessa posição, cursou nível superior e se especializou. A partir dessas informações preliminares, passa-se a descrever a história de vida como foi contada e se fazem as relações com a proposta do estudo em questão.

A primeira dificuldade encontrada era como contar a história de vida de uma pessoa com a mesma intensidade e força da experiência de quem viveu os fatos, colocando-se na posição de protagonista da sua própria história a ser escrita e sem cometer o equívoco de não contemplar todos as nuances desse relato, tarefa que, em um primeiro momento, pareceu um obstáculo intransponível.

Transportar para o papel as falas, os gestos, os olhos mareados e as pausas em silêncio acabaram por transformar o pesquisador em expectador da vida vivida, do relato nu de um acontecimento único, inédito e irreprodutível, após o ocorrido.

Com essa perspectiva, o começo desse relato de história de vida parte dos fragmentos das lembranças de uma infância que se desenvolve no interior do país, agitada por mudanças para localidades diferentes, em decorrência do trabalho de topógrafo do pai. Nessa família havia um pai que era topógrafo, uma mãe enfermeira e um casal de filhos que, naquele momento, morava no interior de Goiás, quando, por volta dos seis anos de idade da menina, essa infância foi marcada pelo assassinato do pai, provavelmente por motivos relacionados ao seu trabalho na demarcação de terras.

Nos dias que se seguiram, a mãe foi acusada de envolvimento no assassinato, presa e torturada para a obtenção da confissão. Nessa condição, teve a tutela dos seus filhos relegada à benesse dos vizinhos em Goiás, até que os familiares, oriundos de Santa Catarina, pudessem chegar à localidade para garantir a salvaguarda das crianças.

Após esse episódio, a mãe e o casal de filhos se transferem para Santa Catarina e, mesmo respondendo ao processo criminal pelo assassinato do pai, a mãe procura retomar a sua vida, começa a trabalhar como enfermeira, casa-se novamente e deixa a casa dos parentes que a acolheram no sul do país.

Devido ao trabalho da mãe, as crianças tinham pouco contato com ela. A menina era mais ativa e gozava de melhor saúde que o irmão, quase sempre acometido por crises de bronquite, chegando a passar por um quadro de meningite. 
Quando chegou aos treze anos, a menina se confrontou com outro acontecimento traumático que marcou sua adolescência: o falecimento de sua mãe, acometida por um câncer.

A convivência com o padrasto não deu certo e o casal de crianças retornou à casa da tia, considerada pela menina como sua mãe adotiva. O irmão, atualmente, ainda mora com os tios e recebe os cuidados deles, pois apresenta um quadro de esquizofrenia que demanda assistência constante. A menina deste relato é a entrevistada deste estudo.

A moça, agora com dezesseis anos, começa a trabalhar. Nas suas palavras: "sempre tive que me virar, sozinha assim pra tudo né [...], fiz faculdade sozinha, [...], sempre ralei mais sozinha assim". Essa solidão perene da entrevistada parece mais próxima da imagem que ela projeta de si. A perda dramática e prematura dos pais, aliada ao processo de separação no casamento, que levou ao afastamento da família do ex-marido, serviu de reforço a sua condição solitária: "é aquilo que eu falo, acabei não perdendo de novo só o ex-marido, eu perdi de novo a família, como se eu tivesse perdido dez irmãos". Em outro momento, essa condição se torna mais explícita:

[...] especialmente eu me sinto muito sozinha, principalmente em certas datas e nossa, pra mim natal e ano novo essas coisas, geralmente nessas datas eu estou no chão, essas datas pra mim é terrível, terrível, terrível. Porque é as datas que tu mais sente essa questão de família assim.

A necessidade de encontrar amparo para o seu isolamento acabalevando ela a estabelecer uma relação pessoal com o medicamento, quase como se esse último fosse outro ser humano. Ou seja, ao conceber o medicamento como alternativa para a fuga dos seus momentos de solidão, parece dar ao medicamento o estatuto de sujeito. Na fala da entrevistada, essa personificação do fármaco pode ser identificada na menção em terceira pessoa do clonazepam.

Eu procuro ele, eu sinto falta dele nesses momentos principalmente assim. Eu me sinto sozinha, é a primeira coisa que eu penso, primeira. Final de semana que eu vejo que vou ficar sozinha é uma coisa automática, não vou dizer pra ti que eu penso assim, uma coisa automática, parece que já "shii". Parece que é automática assim, não, vou apagar eu tenho que apagar [risos]. 
Aos dezoito anos se casa e aos vinte tem seu primeiro filho. Nesse momento, acreditou que a sua vida estava estabilizada, entretanto,

[...] quando eu casei [...], minha vida praticamente parecia estar estabilizada, batalhando com meu marido e tal, mais ai quando tive o primeiro filho, quando ele tinha uns cinco anos acho, cinco pra seis anos, eu comecei a ter uns sintomas, que na época eu não sabia o que que era, eu comecei a passar, passava mal, eu achava que era alguma coisa, nunca passava pela minha cabeça que era algum sintoma de depressão ou coisa assim, e na época meu marido me levava pro hospital e [...] cada um dizia que era uma coisa, há porque eu tinha palpitação, parecia sensação de desmaio e nunca ninguém falava que era alguma coisa em relação a depressão, sempre falavam pra fazer um exame cardíaco ou neurológico,[...] chegavam na emergência [...] Ah tá com distúrbio, eu me lembro que era distúrbio neurovegetativo e nunca tinha uma coisa certa, só que eu passava mal, fisicamente eu passava mal, eu tinha vontade de vomitar, [...] o coração disparava.

No ano de 1997, ano provável do início das crises, havia uma classificação para quadro clínico da depressão no Manual Diagnóstico e Estatístico (DSM) III - R, que se manteve praticamente inalterada até o ano de 1994, ano de lançamento do DSM-IV. Entretanto, o relato de queixas pouco específicas, associadas a sintomas emocionais e orgânicos diversos, podia encaminhar o médico a realizar o diagnóstico do quadro de uma forma genérica, como distúrbio neurovegetativo (DNV), identificado como crise de angustia (FIRMINO, 2012).

Nos casos de DNV, aparecem sinais e sintomas semelhantes de várias doenças, de forma particular, daquelas do sistema cardiocirculatório. Sendo assim, o DNV poderá se constituir em um fator de confusão ou até mesmo poderá induzir a uma indicação clínica inadequada (FIRMINO, 2012). Essa dificuldade pode ser resultante da maneira pela qual aconteciam os tratamentos das crises da entrevistada que, em geral, se passavam conforme o relato:

[...] o que que acontecia, eles me enchiam de calmante, chegando a um ponto de um dia ele [o marido] me levar pro hospital Florianópolis e eu escutar tudo que o médico falava, perguntando pra ele se eu usava drogas, e eu não conseguia responder. Aquilo foi me dando uma angústia, não conseguia mover um dedo, mas eu escutava tudo que o médico falava, e aquilo estava me agoniando, de tanto remédio que acho que eles me deram, eu não conseguia, não conseguia mover um dedo pra falar alguma coisa, pra dizer não, não, não!

A aparente impossibilidade de obter um diagnóstico preciso sobre seu estado de saúde é derivada da incompetência médica na definição de um quadro clínico 
clássico de angústia. Como consequência, têm-se intervenções clínicas inadequadas, adicionadas de possíveis excessos cometidos na emergência dos hospitais, levando a entrevistada a fazer um pedido desesperado ao seu marido:

E ai depois daquele dia eu pedi, implorei pro meu marido que ele nunca mais me levasse pro hospital, e quando acontece alguma coisa até hoje, a gente está separado, mas ele cumpre essa promessa, [...] mas eu não queria mais ir pro hospital, porque eu chegava lá e eles me enchiam de calmante e isso não me ajuda.

Entre o nascimento do primeiro e do segundo filho, passaram-se doze anos, e, nesse tempo, as crises foram se amenizando e a entrevistada conseguia ter um controle melhor dos episódios. A gravidez do segundo filho fora marcada pela dificuldade de "segurar" a gestação e pela necessidade de tratamento para engravidar. Nesse período, ocorreram cinco abortos espontâneos:

Do primeiro filho pro segundo isso [as crises] foi meio que amenizando, fui conseguindo controlar e até então ainda não tinha bem noção do que que era e depois fui no médico, chegaram a conclusão que poderia ser uma depressão, mas nada muito grave até então né. $E$ ai eu tive muita dificuldade de engravidar do segundo filho, não conseguia engravidar, eu engravidava mas não conseguia segurar, tive cinco gravidez, mas perdia. Fiz o tratamento e veio o segundo [filho], tanto que tem a diferença de doze anos de um para o outro.

Seria plausível associar os abortos espontâneos e a dificuldade de engravidar, corroborado pela imprecisão do diagnóstico de uma depressão "nada muito grave", ao fato dos distúrbios neurovegetativos, aparentemente controlados, virem a eclodir em um quadro de depressão pós-parto, quando do nascimento do segundo filho:

Quando eu estava na maternidade, tive ele [o segundo filho] na Santa Helena, eu fiquei lá porque eu fiz cesárea, eu me senti mal à noite e eu pensei em falar pro médico no dia, que eu estava me sentindo mal, só que disse não, estou cansada, vou pra casa. Nossa quando eu cheguei em casa foi terrível assim, eu não conseguia segurar ele nem pra amamentar, eu ia amamentar ele e eu tinha vontade de jogar ele na parede, foi horrível, foi horrível não tinha força, horrível tive uma depressão pós-parto terrível.

A entrevistada menciona que um médico "de depressão" fez a escolha do tratamento para a depressão pós-parto com um remédio natural, porém surtiu pouco efeito e ela não conseguiu amamentar. Diante desse quadro, a pediatra recomendou que a alimentação do segundo filho fosse realizada com a utilização da mamadeira,

Cad. de Pesq. Interdisc. em Ci-s. Hum-s., Florianópolis, Santa Catarina, ISSN 1984-8951 v.15, n.106, p. 117-139 - jan./jun. 2014 
e a entrevistada iniciou seu tratamento com o uso de um "remédio forte". A partir desse tratamento, a entrevistada começa a vivenciar períodos cíclicos de melhora e recaída, em intervalos quase regulares, que se seguem até a separação no casamento:

\begin{abstract}
A pediatra falou não, a gente aconselha amamentar, mas desse jeito ela não tem como, ela tá se destruindo, passaram ele pra mamadeira e eu comecei a tomar remédio forte e dali em diante eu comecei assim, melhorei né, mas sempre em ciclos sabe, passava um ano bem, daqui a pouco caía de novo, um ano bem, caía de novo. E depois veio a separação...com cinco anos, com três anos estava o segundo filho, eu me separei...e ai... depois de um ano de separação ai veio bem forte assim, bem forte mesmo.
\end{abstract}

A dificuldade em obter um diagnóstico preciso sobre o quadro clínico da entrevistada vem se arrastando por quase vinte anos, e, nesse período, seu estado de saúde foi atribuído a um distúrbio neurovegetativo, com aconselhamento para realizar exames cardíacos ou neurológicos. Depois do nascimento do primeiro filho, ela menciona um diagnóstico de depressão não muito grave, mas as crises continuaram com menor intensidade até o nascimento do segundo filho, quando ela teve um quadro de depressão pós-parto. Após iniciar o tratamento com a medicação, ela entra em um processo (quadro clínico) cíclico de melhora e de piora da depressão. Após um ano da separação no casamento, passa por uma forte crise depressiva, necessitando ser internada por trinta dias em uma clínica de reabilitação. Conforme relatado pela informante, nessa fase começaram os sintomas da síndrome de pânico.

As crises de pânico eram fortes e a impossibilitavam de realizar qualquer atividade, mesmo as mais cotidianas, como dirigir um automóvel ou assistir a uma aula na faculdade. Foram três episódios da síndrome de pânico e, na terceira crise, ela foi aconselhada ao internamento para reabilitação em uma clínica. Nessa época, ela já fazia uso esporádico do clonazepam para dormir, sem especificar por quanto tempo vinha utilizando. Depois desse tempo na clínica, o uso de clonazepam e de outros medicamentos foi constante durante quatro ou cinco anos. No decorrer de um ano, era possível suprimir o uso de alguns medicamentos, porém, isso não acontecia com o clonazepam, e os períodos de melhora e recaída continuavam ocorrendo: 
Eles me levaram... foi onde eu fiquei trinta dias... primeira internação, ali também já tomava o clonazepam lá, dali sempre assim, vai fazer cinco anos, quatro anos direto, fora as outras medicações, direto assim, depois dali eu já tive mais duas internações, mas o clonazepam direto, direto, eu tomava o clonazepam, quando eu saí dali, eu saí bem mas era eram ciclos, ficava um ano bem quando chegava, era engraçado assim, foi em fevereiro, eu acho, março, eu passava o ano inteiro bem, podia até ir cortando alguns outros remédios, mas o clonazepam eu não conseguia cortar eu tomava ele igual a tic-tac, igual, tanto que quando chegava em março, aquela outra época, eu caía de novo (grifo nosso).

A indefinição do diagnóstico da entrevistada, associado ao tratamento prolongado com vários medicamentos, entre eles, o clonazepam, resultaram na utilização equivocada do medicamento, na inadequada retirada dos medicamentos que atuam sobre o Sistema Nervoso Central (SNC), e também no surgimento da dependência química, física e psicológica, relacionada ao clonazepam. Essa condição de dependência interfere na maneira como a paciente enfrenta situações cotidianas, produzindo um estereótipo da maneira como ela é vista pelas pessoas do seu ciclo de amizades e convívio:

Eu estava na sala de espera, pra consultar, enquanto eu estava esperando
pro médico me consultar eu tomei uma cartelinha inteira (de clonazepam),
eu estava esperando disse não, tomando acartelinha inteira parecia, parecia
não, era uma viciada mesmo e quando entrei no consultório eu mal
conseguia falar, tomei uma cartelinha inteira, eu hoje...eu digo pra ti que eu
consigo ficar sem ele assim, mas eu tenho que saber que alguém, por
exemplo meu filho guarda em casa, entendeu. Eu já consigo passar o dia
todo sem ele, mas aqui na universidade tudo, na época as meninas até
brincavam: Que é a traficante, na bolsa dela sempre tem, sempre! (grifo
nosso).

Nesse momento a entrevistada abre a sua bolsa e mostra uma nécessaire com várias cartelas de diversos medicamentos, pela coloração dos comprimidos, das caixas e das cartelas é possível identificar ao menos cinco tipos diferentes de medicamentos. E, em seguida, dentro de uma porta cápsulas, são identificados dois comprimidos de clonazepam, além de três outros remédios.

De modo paradoxal, a dependência química e física da entrevistada parece que está quase sob o controle, porém, após nove anos de uso do clonazepam, o traço de dependência psicológica ainda tem grande influência no cotidiano dela:

Eu tenho que saber que está aqui (o clonazepam), eu não tomo, mas tenho que saber que está aqui. [...], porque às vezes eu nem preciso tomar, mas eu tenho que saber que ele está na bolsa. Eu ainda não consigo sair de casa sem saber, que eu não tenho na bolsa, se eu vou em algum lugar ou 
troco de bolsa é a coisa mais engraçada, eu posso não ter nada, mas eu já começo a sentir os sintomas, parece que já estou sentindo sabe, só em saber que eu estou sem ele na bolsa. Até falei pro médico, é a coisa mais engraçada, eu começo a sentir algo só por saber que não está e eu não tenho nada, mas ainda tenho aquela coisa eu mesmo me simulo a situação e não tem, de repente só em colocar na bolsa já melhorei.

No relato da entrevistada, pode-se destacar a presença de dois modelos explicativos, isto é, de significados atribuídos a um mesmo episódio da doença, incluindo-se nestes as noções sobre a causa, o diagnóstico e até o tratamento (MARTÍNEZ, 2010). Esses dois modelos explicativos, que aparecem no relato da entrevistada, permitem colocar, de forma simétrica, as diferentes percepções sobre a doença, sendo eles: um com enfoque biológico, e outro com enfoque mais holístico. Por meio de tais modelos, acredita-se que é possível compreender de que maneira a entrevistada interpreta o desenrolar dos contextos relacionados ao seu estado de saúde.

O primeiro modelo é exemplar de uma fórmula narrativa hegemônica mais próxima da linguagem biomédica (MARTíNEZ, 2010). Nele, a entrevistada busca transformar seu mal-estar em uma doença, com a possibilidade de silenciar, pela enunciação do diagnóstico, os conflitos existentes em sua história de vida:

No começo foi uma coisa que surgiu, nem eu tinha noção do que que era, que os médicos sempre dizem pra mim que é em decorrência da minha história de vida e junto com a questão emocional e com a questão genética porque na minha família tem muita gente que tem. Tenho primos, primas que tem o mesmo quadro que eu, tem muita gente que tem, meus tios, eu tenho muita gente na minha família com o mesmo histórico (grifo nosso).

Pode-se notar outra narrativa sobre as suas adversidades, mais humanizada e relacionada aos condicionantes sociais:

Eu acho que têm haver com a questão emocional mesmo, questões de vida,
tem muita coisa que eu passei que está muito mal explicado. [...] porque eu
passo minha vida inteira assim não querendo mexer muito no passado, não
se seria bom esse tipo de coisa. E então não sei bem ao certo, acho que é
uma mistura de tudo isso, acho que é tudo que eu passei, porque foi uma
infância difícil, uma adolescência. Na infância perdi meu pai de uma forma
muito difícil, na adolescência perdi minha mãe de uma maneira difícil, eu
tenho muitas coisas difíceis, tem esse meu irmão com esquizofrenia, minha
tia tem setenta e sete anos, meu tio tem oitenta e oito eu sei que é uma
coisa que vou ter que enfrenta e eu não tenho estrutura pra enfrentar, isso é
uma coisa que todos os dias me pega. [...] estou separada, a questão de
estar sozinha é uma coisa que me deixa muito, muito assim. 
A maneira como a trajetória de cada pessoa é construída interfere nas escolhas e decisões de todo o caminho a ser percorrido, agregando maior ou menor dificuldade para realizar esse percurso. A perda de entes queridos na infância e na adolescência da entrevistada, por certo, não foram escolhas dela, mas fazem parte de um passado repleto de conflitos, de questões em aberto.

O temor descrito pela entrevistada diante da realidade do envelhecimento dos tios e a necessidade de assumir sozinha o tratamento do irmão esquizofrênico parecem propiciar um ambiente favorável à fuga e ao distanciamento da realidade pela via do uso do medicamento:

\begin{abstract}
Eu hoje procuro muito o clonazepam, porque a última vez que eu estive agora, esses três meses que eu fiquei afastada eu tenho até um laudo no hospital agora que eles colocaram lá que foi tentativa de suicídio, e eu tomei dezessete comprimidos ai eles me perguntaram, até comecei a rir quando estava lá como tentativa de suicídio, porque na verdade eu não penso em me matar eu quero só apagar, que é quando eu recorro ao clonazepam, quando eu estou no meu desespero eu quero sair do ar só, quero parar de pensar, quero dormir, quero apagar mesmo. [...] realmente na hora, quando você está no desespero você não pensa nisso, porque eu fico muito desesperada, a solidão, essa coisa de estar sozinha, não poder resolver as coisas, pra mim a minha fuga é o clonazepam.
\end{abstract}

O uso do clonazepam, na tentativa de silenciar as dificuldades do dia a dia, parece ser um porto seguro para a entrevistada, diante do bem estar proporcionado pelo medicamento e da aparente ausência de reações adversas nos dias seguintes ao uso. Essa busca de mascarar e até mesmo de eliminar a todo custo o sofrimento remete à sociedade fictícia do Admirável Mundo Novo, onde os efeitos proporcionados pelo SOMA e a busca da felicidade se sobrepõem às adversidades da vida humana. De forma similar a uma ração diária, o uso crônico do clonazepamse coloca como meio de sobrevivência aos destemperos da vida cotidiana (HUXLEY, 2009).

A reorganização dos estados de ânimo em doenças objetiva compor uma lógica de dissociação, que tem seu poder apoiado em um mundo de alterações neuroquímicas. Nessa lógica, ocorre a confluência dos processos de medicalização e mercantilização, os quais se apoiam e se reproduzem, gerando ilusões e fetiches. Desse modo, se por um lado, desintegram-se as relações sociais que podem produzir as aflições e os estados de ânimo, por outro, os agentes são envolvidos em 
redes de consumo, relações mercantis e discursos hegemônicos (MARTíNEZ, 2010).

Após nove anos utilizando o clonazepam de maneira crônica, observa-se o aparecimento das sequelas, provavelmente comórbidas, ao uso desse medicamento:

\begin{abstract}
A vantagem do clonazepam pra mim que eu vejo nessa coisa toda que ele me apaga, mas quando eu acordo bem. Não acordo com aquela coisa nauseada, ele só me apaga, quando eu acordo parece que não tenho nada, [...] só fechei o olho e, acho que é por isso que ele me viciou, me deixou [...] só dormi um soninho assim sabe, e...e... não sei se foi isso que acabou me deixando tão dependente dele, e claro agora estou ficando com sequela dele, dos roxos que te falei, das manchas roxas, os esquecimentos que antes não aconteciam, agora o que que acontece, quando acontece isso comigo eu não lembro de nada, isso não acontecia antes, agora já está tendo sequelas que antes eu não tinha, mas agora é por causa do abuso, do meu abuso com ele. Então, das últimas vezes aconteceram coisas que eu só sei porque as pessoas me contaram, não lembro, realmente não lembro, foi onde começou a me assustar do que realmente pensei espera aí né.
\end{abstract}

Durante todo esse tempo de tratamento, a entrevistada já havia sido diagnosticada como portadora de distúrbio neurovegetativo, depressão leve, depressão pós-parto, síndrome do pânico e, pouco antes de se separar do marido, recebeu o diagnóstico de transtorno bipolar. As idas e vindas aos consultórios médicos parecem ter contribuído pouco para o esclarecimento do quadro clínico da entrevistada, e tampouco apresentaram evolução na forma de conduzir o tratamento dela por quase vinte anos:

\begin{abstract}
Sempre foi assim, daí fazia terapia, aí tomei vários tipos de medicamentos fluoxetina, paroxetina, e... nossa, vários, vários, vários. E sempre pra dormir, algum tipo de calmante, ai até chegar agora depois da separação, antes um pouquinho da separação, ai já diagnosticaram que eu era bipolar também, aí deram remédio pra bipolaridade, estabilizador de humor nossa já tomei muito tipo de remédio, estabilizador de humor, tanto que um quem tem ali é pra isso o oxcarbazepina.
\end{abstract}

Nesse ínterim, a entrevistada parece não ter percebido melhora importante do seu quadro clínico, tampouco parece concordar com a opção do seu terapeuta em recomendar para ela o uso de um estabilizador do humor. Em seu momento atual, ela parece desconhecer a pessoa na qual se tornou, sendo visível o seu desinteresse por qualquer atividade pessoal ou profissional, restando-lhe a responsabilidade com os filhos, talvez o único motivo capaz de the dar força para continuar:

Cad. de Pesq. Interdisc. em Ci-s. Hum-s., Florianópolis, Santa Catarina, ISSN 1984-8951 v.15, n.106, p. 117-139 - jan./jun. 2014 
Só que eu acho, eu acho que o estabilizador de humor pra mim ele só piorou, ele me deixou mais depressiva, [...] na teoria do médico, [...] tem que estabilizar porque aí quando eu estou estabilizada eu não ficaria tão depressiva, mas ele acha que eu sou muito agitada, [...] e eu achei o contrário pra mim, que eles quiseram estabilizar essa coisa de estar agitada, e, eu, parece que eu perdi minha identidade, eu fico sempre depressiva, muito mais depressiva, já falei isso pra ele. Eu deixei de ser tão agitada, mas em comparação com esses últimos anos, eu pra mim, eu não tenho mais animo pra nada. Eu era uma pessoa que estudava, sempre fui de estudar de manhã, de tarde, de noite, [...] eu vivia correndo até meu próprio ex-marido falava pra mim, você parou, tua vida parou, [...], tu parou no tempo, e eu falo mesmo, eu me sinto parada, eu não tenho vontade de estudar, eu não tenho vontade [...], não tenho vontade de fazer mais nada.

Para Martínez (2010, p. 114), parece haver "uma biopolítica das doenças leves, os mal-estares e as adversidades humanas". Em outros termos, existe uma estratégia de silenciamento dos conflitos e sofrimentos cotidianos do ser humano, que são traduzidos em discursos e teorias medicalizantes, resultando, em geral, no aumento do consumo de medicamentos e, nem sempre, na melhora do quadro clínico do paciente.

O sentimento da entrevistada, de não estar conectada à realidade, transforma atividades diárias em pesadas obrigações a serem cumpridas. Isso aparece de maneira mais incisiva quando a entrevistada não mais se reconhece, nem mesmo em seu trabalho. A angústia e o desejo de fuga aparecem atravessados na fala da entrevistada, diante da perspectiva de si mesma:

Só estou voltando porque a médica da perícia disse pra mim que eu tinha que voltar porque eu não tenho vontade nenhuma, tenho até vontade de chorar falando contigo... [olhos mareados], a minha vida parou assim.

Se tu dissesse pra mim, o que tu está com vontade de fazer agora?

Eu por mim tomava uma caixa de clonazepam e dormia a semana toda, não tenho vontade nenhuma [...] eu estou porque eu tenho dois filhos tenho um de vinte e muito mais pelo de nove sabe, que eu sei que precisa de mim.

Nossa isso aqui oh, esses planilhas sabe o que é você não ter vontade, e o pior o que mais me angustia é que eu não sou assim, que eu olho pra trás e vejo.

A retirada do medicamento clonazepam consiste em uma etapa difícil, muitas vezes demorada e cheia de percalços. Demanda um comprometimento do paciente, da família e do profissional durante esse período (RANG, 2007).

Da mesma forma, visualizada por Orlandi e Noto (2005), quando demonstram, em seu estudo, haver facilidade na obtenção de receituário para os 
benzodiazepínicos, a entrevistada relata parte de sua experiência na retirada do medicamento:

Ele [o médico] falou que era pra tirar tudo de mim, meu filho tirou, aquele ali eu tenho porque eu tenho escondido, [...] eles só ficam a noite quando eu preciso, ai aqueles ali eu tenho porque eu tenho escondidinho, eu tenho uma máfia que me fornece. Nas primeiras semanas eu fiquei quase louca, ai eu falei pra minha família, não adianta tirar eu sei onde tem [...] vou atrás eu sei onde é que tem, igual a drogada mesmo...

A dependência e a tolerância estão relatadas na literatura especializada como uma ocorrência rara e incomum (RANG, 2007), porém se encontram indícios desse fato no estudo de Firmino (2012), e, de maneira mais declarada, nas falas da entrevistada, quando cita o aumento gradual no uso do clonazepam:

Pra insônia, tomava dois miligramas [...]. Ah, hoje se eu tomar dois, três não me faz nem cosquinha, já cheguei a tomar três, quatro, cinco. Se eu tomar um não faz efeito, dois não faz efeito. Aí quando eu me entupo mesmo aí, pra fazer efeito mesmo, já fiquei dois dias dormindo direto, não acordar pra nada, e quando é assim que acordo toda roxa.

Em determinado momento, a entrevistada relata ter solicitado ao médico a realização de algum exame para comprovar a disfunção cerebral, afinal, tantos transtornos, melhoras e recaídas, poderiam, no entendimento da entrevistada, ser comprovadas a partir de um exame.

Cheguei até fazer tomografia, eu pedi pro médico pelo amor de Deus, que eu queria fazer uma tomografia, ressonância o que fosse porque eu tinha que ter alguma coisa na minha cabeça, porque eu levei um tombo uma vez eu levei vinte e sete pontos na cabeça. [...] tem alguma coisa, deve ter dado algum coagulo, faz uma tomografia que deve ter alguma coisa. [...] eu queria tanto que desse alguma coisa, [...] mas eu estava crente que ia dar alguma coisa pra explicar isso tenho certeza, estava crente que ia dar um tumor. Tinha que dá alguma coisa, eles vão ver que na minha cabeça tinha alguma coisa, ai agora da última vez o médico mandou fazer outra, fiz outra mas nada. O biológico está tudo normal, e aonde te deixa mais nervosa, mais agoniada ainda, que como que não tem nada, nem um fio solto nada.

Antes de fechar a entrevista ainda foi possível, para a entrevistada, externar sua perspectiva para o futuro, diante de uma necessidade de mudança que a levasse a retomar o controle de sua vida. A possibilidade de se reencontrar, de se sentir viva e voltar a ser a protagonista de sua vida está expressa na seguinte fala:

Ah, eu queria, olha eu queria mudar, eu queria tentar voltar um pouquinho a ter o animo que eu tinha antes, eu acho que esse desânimo que eu sinto por dentro que está me matando, essa falta de ânimo, de não ter vontade de fazer as coisas, não ter mais brilho nas coisas é que me mata. Eu sinto muita falta da pessoa que eu era antes assim, de ter aquele gás que eu

Cad. de Pesq. Interdisc. em Ci-s. Hum-s., Florianópolis, Santa Catarina, ISSN 1984-8951 v.15, n.106, p. 117-139 - jan./jun. 2014 
tinha antes assim, de não ter, de estar sempre querendo buscar alguma coisa, não ter tempo ruim para nada assim. A impressão que tenho mesmo é que eles acham que eu sou bipolar, porque realmente são duas pessoas. É uma de antes e uma de hoje assim, eu falo mesmo pro médico, realmente são duas pessoas porque é uma pessoa que está aqui que não sou eu, não sou eu.

A discussão se encerra nesse ponto, porém, a entrevista proporcionou um volume muito maior de informações sobre aspectos a serem tratados e que foram suprimidos por estarem fora da abrangência do presente estudo.

\section{Conclusão}

Não haveria possibilidade de desenvolvimento da vida fora dos laços com o outro. Parece clara a necessidade do estabelecimento de vínculos entre o indivíduo e o meio com o qual ele interage. Como afirma Canguilhem (2009, p. 130), "o ser vivo e o meio não podem ser chamados normais se são considerados separadamente", somente pode afirmasse-pode-se dizer de um ser vivo que é normal se é vinculado com seu meio, se são consideradas as soluções morfológicas, funcionais e vitais a partir das quais responde as demandas que o meio the impõe, pois "o normal é poder viver num meio em que flutuações e novos acontecimentos são possíveis".

Em uma sociedade voltada para o consumo de modelos de saúde, a imprecisão de parâmetros capazes de definir o que é normal e o que é patológico abre espaço para o surgimento de relações simbólicas e, por vezes, distorcidas entre o consumidor e a mercadoria. Quando a relação mercantil extrapola os limites da transação comercial, podem ser observadas situações que perpassam o campo econômico, médico e social, chegando ao ponto de se imaginar que a compra de um medicamento-mercadoria é a forma mais eficaz de resolver os problemas humanos.

No caso concreto aqui analisado, foi possível observar que o medicamento ocupa um papel social fundamental no modo como a entrevistada se vincula consigo mesma e com seu sofrimento. Para ela, a relevância da medicação parece estar dada pelo modo como se vincula subjetivamente a essa mercadoria. Diante da impossibilidade de dar sentido a seu mal-estar, aos seus sintomas, o medicamento parece resolver, no imaginário da entrevistada, todas as suas dificuldades em se situar no laço social, em se relacionar com os outros. O medicamento substitui, assim, as interações e os laços sociais que são essenciais para que cada um de nós

Cad. de Pesq. Interdisc. em Ci-s. Hum-s., Florianópolis, Santa Catarina, ISSN 1984-8951 v.15, n.106, p. 117-139 - jan./jun. 2014 
possa se construir como sujeito. Uma estratégia pela qual a entrevistada opera a substituição das relações humanas e dos conflitos cotidianos pelo medicamentomercadoria parece ser, como já foi mencionado, a identificação da medicação com um sujeito.

Esse processo de personificação das coisas e de coisificação das pessoas parece encobrir a fragilidade das relações humanas e sociais dos últimos tempos. Tal fragilidade se torna mais evidente a partir do momento em que um indivíduo opta por buscar apoio para sua condição pessoal, dentro de um determinado contexto social, utilizando a via do medicamento, pela qual passa a se referir, inclusive, em terceira pessoa (BARROS, 2010; CAPONI, 2012).

Em vista desse processo nebuloso e confuso, situa-se a dificuldade imposta a um paciente, na sua busca pela remissão de um quadro clínico, não raras vezes decorrente de uma trajetória de vida, permeada por contextos conflituosos ou até mesmo adversos. Ao realizar o diagnóstico pautado pelo modelo biologicista e medicalizante, o profissional desconsidera qualquer elemento ou condição diferente dos parâmetros biológicos. Nesse sentido, os contextos sociais são descartados, e a vivência do paciente é transmutada em sintomas clínicos, mascarando e, até mesmo, silenciando o sofrimento vivenciado de maneira cotidiana.

Dentro do panorama brasileiro, foram visitados importantes estudos, como os de Alvarenga (2008), Carlini (2006), Firmino (2012), Mendonça e Carvalho (2012), Orlandi e Noto (2005) e Noto (2002), que propiciaram a compreensão da interferência dos contextos sociais na complexidade dos casos clínicos dos pacientes crônicos de BZD, assim como possibilitaram a contextualização de um perfil sociodemográfico desses pacientes e de suas principais características.

A partir desse levantamento foi possível visualizar as características mais frequentes dentro desses estudos. Os pacientes crônicos de BZD, em geral, são mulheres, com quarenta anos ou mais, fazem uso do medicamento por períodos superiores a dois anos, apresentam um quadro clínico complexo com diagnósticos divergentes ou imprecisos, iniciaram o uso do BZD sem orientação especializada, ou seja, quando amigos ou familiares compartilham o remédio, e vivenciam contextos sociais adversos.

A história de vida trazida neste trabalho ilustra de maneira contundente o sofrimento vivido pela informante. Com um caminho marcado por perdas de entes 
queridos, sofrimento físico e psíquico, medicalização de sua vida e indefinição de um diagnóstico por mais de vinte anos, os resultados apontam para uma completa transformação na sua personalidade, chegando ao ponto dela mesma não se reconhecer mais.

Diante desse relato, não há espaço para a vitimização da entrevistada, pois colocá-la nessa posição esgotaria por completo qualquer autonomia e dignidade remanescente, considerando que, em algum momento, ela teve livre direito de escolha sobre seu tratamento, podendo abdicar de uma ou de outra conduta médica. Ainda assim, culpabilizá-la por determinadas escolhas feitas ou impostas a ela apenas tornaria o entendimento do processo mais doloroso, colocando sobre seus ombros a responsabilidade pelo seu próprio sofrimento. Dessa forma, qualquer julgamento moral a partir da perspectiva de quem não vivenciou o sofrimento da entrevistada não se faz oportuno, nem mesmo necessário.

Cabe realmente uma escuta qualificada, buscando nas entrelinhas de seus relatos o que a entrevistada considera importante para o seu futuro, de modo a oferecer o suporte adequado para que ela consiga construir os alicerces e enfrentar os desafios relacionados ao envelhecimento dos tios, da criação dos filhos e do tratamento do irmão. Parece oportuno apresentá-la a uma alternativa terapêutica menos preocupada com o tratamento medicamentoso e mais voltada para a compreensão das dificuldades dela no entendimento da sua história de vida, possibilitando seu reencontro consigo mesma. A dependência química experimentada pela entrevistada a transformou em réu e algoz de sua própria existência, confinando-a, nos últimos vinte anos, em uma cela química sem janelas.

Se a história de vida dessa senhora fosse um caso isolado, ainda assim não seria moralmente nem eticamente aceitável tal história marcada pelo abuso de medicamentos. Porém, os dados ora levantados neste trabalho apontam para a disseminação e as proporções dessa realidade. As informações coletadas no Sistema Nacional de Gerenciamento de Produtos Controlados (SNGPC) corroboram a ocorrência de uma elevação sustentada do consumo de BZD e, de maneira mais expressiva, do clonazepam. Ressalta-se que esses dados ainda não contemplam as farmácias de manipulação e nem os dispensários e congêneres do SUS, não havendo possibilidade de dimensionar com precisão a amplitude do problema (BRASIL, A., 2011). 
Outra fonte de dados expressiva, o relatório do INCB, aponta para uma produção mundial em torno de dez toneladas anuais de BZD, distribuídos em mais de cento e quarenta países. Ainda é possível verificar, nesse relatório, as principais formas de desvio, contrabando e falsificação desses medicamentos, chegando a relatos das diversas formas de obtenção ilícita do mesmo, o que também se confirmou no relato da entrevistada (INTERNATIONAL NARCOTICS CONTROL BOARD, 2012).

Como balanço desse volume de informações seria factível estabelecer uma forte relação entre a história de vida de uma paciente, permeada por contextos sociais adversos, e a transformação dessa vida vivida, quando atravessada por processos medicalizantes, em uma experiência dolorosa e absolutamente sofrida. A existência de dados qualitativos e de estudos quantitativos sobre o consumo de BZD propiciam a construção de um panorama que exige urgência na implementação de medidas para salvaguardar a saúde dos pacientes, sob pena de se arcar com os custos do tratamento de dependentes químicos, físicos e psicológicos.

A ligação entre a história de vida de um indivíduo e os seus mal-estares é tecida por sofrimentos advindos de relações sociais, e por vivências conturbadas que se passam no decorrer dessa história. Desprezar esses imbricamentos significa não atender o paciente na sua plenitude, uma vez que não parece adequado concebê-lo de forma dissociada do meio onde vive. 


\section{Referências}

ALVARENGA, J. M.; et al. Prevalência e características sociodemográficas associadas ao uso de benzodiazepínicos por idosos residentes na comunidade: projeto Bambuí. Revista Brasileira de Psiquiatria, São Paulo, v. 30, n.1, mar. 2008.

ANGELL, M. A verdade sobre os laboratórios farmacêuticos. Rio de Janeiro: Record, 2007.

BARROS, J. A. C. Ampliando espaços para a medicalização: instrumento para desfrute de melhores níveis de saúde? In: CAPONI, S. et al. Medicalização da vida: ética, saúde pública e indústria farmacêutica. 1. ed. Palhoça: Ed. Unisul, 2010.p. 8995.

BECKER, H. S. Métodos de Pesquisa em Ciências Sociais. São Paulo: Hucitec, 1993.

BRASIL, Agência Nacional de Vigilância Sanitária. Boletim de Farmacoepidemiologia do SNGPC,Brasília, v.1, n.1. 2011.

. Ministério da Saúde. Secretaria de Políticas de Saúde. Departamento de Atenção Básica. Política nacional de medicamentos 2001/Ministério da Saúde, Secretaria de Políticas de Saúde, Departamento de Atenção Básica - Brasília: Ministério da Saúde, 2001.

CARLINI, E. A. et al. II Levantamento domiciliar sobre o uso de drogas psicotrópicas no Brasil: estudo envolvendo as 108 maiores cidades do País: 2005. São Paulo: Paginas \& Letras, 2006.

CANGUILHEM, G. O normal e o patológico. 6. ed. Rio de Janeiro: Forense Universitária, 2009.

CAPONI, S. Loucos e Degenerados: uma genealogia da psiquiatria ampliada. 1. ed. Rio de Janeiro: Ed. FIOCRUZ, 2012.

FIRMINO, K. F. et al. Utilização de benzodiazepínicos no Serviço Municipal de Saúde de Coronel Fabriciano, Minas Gerais. Ciência \& Saúde Coletiva, Rio de Janeiro, v. 17, n. 1, p. 157-166, jan. 2012. Disponível em:

$<$ http://www.scielo.br/scielo.php?pid=S1413-

81232012000100018\&script=sci_arttext>. Acesso em: 15 ago. 2012.

GIL, A. C. Estudo de caso: estratégia de pesquisa. 1. ed. São Paulo: Atlas, 2009.

HUXLEY, A. Admirável mundo novo. São Paulo: Globo, 2009.

INTERNATIONAL NARCOTICS CONTROL BOARD.Report of the International Narcotics Control Board for 2011.New York, 2012a. 
MARTÍNEZ, H. A. A medicalização dos estados de ânimo: o consumo de antidepressivos e as novas biopolíticas das aflições. In: CAPONI, S.et al. Medicalização da vida: ética, saúde pública e indústria farmacêutica. 1. ed. Palhoça: Ed. Unisul, 2010.p. 111-134.

MENDONÇA, R. T.; CARVALHO, A. C. D. O papel de mulheres idosas consumidoras de calmantes alopáticos na popularização do uso destes medicamentos. Revista Latino-Americana de Enfermagem, São Paulo, v.13, n. 2, p. 1207-1212, nov./dez. 2005. Disponível em: <http://www.scielo.br/pdf/rlae/v13nspe2/v13nspe2a16.pdf>. Acesso em: 05 ago. 2012.

NOTO, A. R. et. al. Analysis of prescription and dispensation of psychotropic medications in two cities in the State of São Paulo, Brazil. Revista Brasileira de Psiquiatria, v.24, n.2, p. 68-73, jun. 2002.

ORLANDI, P.; NOTO, A. R. Uso indevido de benzodiazepínicos: um estudo com informantes-chave no município de São Paulo. Revista Latino Americana de Enfermagem, São Paulo, v. 13,p. 896-902, set./out. 2005. Disponível em: <http://www.scielo.br/pdf/rlae/v13nspe/v13nspea18>. Acesso em: 04 ago. 2012.

RANG, H. P.; DALE, M. M. Farmacologia. 6 ed. Rio de Janeiro: Elsevier, 2007.

YIN, R. K. Estudo de caso: planejamento e métodos. Trad. Daniel Grassi. 2. ed. Porto Alegre: Bookman, 2001.

Artigo:

Recebido em: 22/09/2013

Aceito em: 04/07/2014 